\title{
AVALIAÇÃO DA CRIATIVIDADE EM GRADUANDOS DO CURSO DE PSICOLOGIA
}

\author{
Marta Luísa da Cruz Alves \\ Psicóloga. Universidade Guarulhos. \\ Paulo Francisco de Castro \\ Doutor em Psicologia Escolar e do Desenvolvimento Humano, Mestre em Educação, Psicólogo. \\ Universidade Guarulhos e Universidade de Taubaté.
}

\begin{abstract}
Resumo
A criatividade configura-se como importante capacidade humana em várias áreas de atuação, inclusive no trabalho do psicólogo. O presente artigo objetiva descrever a criatividade em um grupo de estudantes do Curso de Psicologia, no sentido de verificar se a formação na área pode criar condições para o desenvolvimento do potencial criativo. Participaram do estudo 75 acadêmicos, distribuídos igualmente em três grupos, com alunos do primeiro, quinto e décimo semestres, com idade entre 18 e 59 anos, que responderam ao Teste de Torrance - Avaliação da Criatividade por Palavras, de acordo com as especificações técnicas do referido instrumento. Após avaliação dos testes, os resultados dos três grupos foram estatisticamente comparados e os principais resultados indicaram maior índice criativo nos formandos do curso, principalmente no que tange à fluência - capacidade em cultivar um número abundante de ideias e Originalidade - habilidade para produzir ideias novas ou incomuns.
\end{abstract}

Palavras-chave: criatividade; avaliação psicológica; estudantes universitários.

\section{ASSESSMENT OF CREATIVITY IN PSYCHOLOGY UNDERGRADUATE STUDENTS}

\begin{abstract}
Creativity is an important human faculty in several performance areas, including the work of a psychologist. This article aimed to describe creativity in a group of Psychology undergraduate students in order to verify whether their professional development fosters creative potential. The study comprised 75 students, equally distributed in three groups from the first, fifth and tenth terms, aged 18 to 59, who were submitted to the Verbal TTCT (Torrance Test of Creative Thinking): Thinking Creatively with Words, following technical specifications of this tool. Further to test evaluation, results of the three groups were statistically compared and the main results showed higher creativity index in senior students, mainly regarding Fluency ability to produce a large number of ideas, and Originality - ability to produce new and infrequent ideas.
\end{abstract}

Keywords: creativity; psychological assessment; college students. 


\begin{abstract}
Resumen
La creatividad se configura como una capacidad humana importante en varias áreas, incluso en el trabajo del psicólogo. El objetivo de este artículo es describir la creatividad en un grupo de estudiantes de la carrera de Psicología para verificar si la formación en el área puede crear condiciones para el desarrollo del potencial de creatividad. Participaron del estudio 75 estudiantes, con edades entre 18 y 59 años, distribuidos igualmente en tres grupos formados por alumnos del primero, del quinto y del décimo semestres, los cuales contestaron al Test de Torrance - Evaluación de la creatividad por palabras, según las especificaciones técnicas de dicho instrumento. Después de la evaluación de los tests, se compararon los resultados de los tres grupos estadísticamente y los principales resultados indicaron un mayor índice creativo en los estudiantes que estaban por graduarse, principalmente en lo que concierne a la Fluidez - capacidad de cultivar un gran número de ideas -, y a la Originalidad - habilidad de producir ideas nuevas o inusuales.
\end{abstract}

Palabras clave: creatividad; evaluación psicológica; estudiantes universitarios.

\title{
INTRODUÇÃO
}

É inegável a participação da criatividade no desenvolvimento humano. Por isso, se pensa na importância de relacionar a participação da criatividade na formação do psicólogo, visto ser uma profissão que se dá numa incessante interação terapeuta/cliente e exige uma percepção ampla e atuação precisa na promoção das capacidades e habilidades do outro, para que trilhe seu caminho de desenvolvimento de forma integralmente saudável.

Perceber-se e compreender-se enquanto ser que carrega intrinsecamente a capacidade criativa e estar ciente das possibilidades de desenvolver esta capacidade é fundamental para o psicólogo. O profissional da área de Psicologia pode usar sua capacidade criativa como ferramenta para a promoção de situações em que o cliente desenvolva, em si, esta capacidade, discernindo, escolhendo, criando. Para Torrance (1965 citado por Alencar, 1995, p. 29) "criatividade é o processo de tornar-se sensível a problemas, deficiências, lacunas no conhecimento, desarmonia; identificar a dificuldade, buscar soluções, formulando hipóteses a respeito das deficiências; testar e retestar estas hipóteses; e, finalmente, comunicar os resultados".

Eis, enfim, em que se baseia a atividade do psicólogo, Alencar e Fleith (2003) explicam a importância de se estimular a expressão criativa, em vários contextos, preparando os sujeitos para pensar e agir de forma inovadora. Deste modo, pode-se planejar intervenções a fim de promover condições favoráveis ao desenvolvimento da criatividade.

Neste sentido todos os envolvidos no processo terapêutico podem se beneficiar. Por outro lado, por ser um tema em que muitas abordagens se debruçaram para compreendê-lo, trazê-lo à tona com uma perspectiva específica 
e relacioná-la aos estudos já existentes sempre é uma forma de enriquecer, ou, se for o caso, refutar, e se possível, CRIAR.

A investigação sobre criatividade envolve grande variedade de material a ser estudado, indicando a necessidade de uma visão integradora das informações disponíveis sobre o fenômeno criativo. A despeito da necessidade de organização do material sobre o assunto, sintetiza-se a definição de criatividade como sendo um potencial humano, fruto da existência e evolução do Homem, que possibilita a criação de ideias e produtos. Como consequência de tal processo, o ser humano adquire liberdade e autonomia para desenvolver suas atividades e tarefas (Sakamoto, 2000). Para Justo (2001), fluência, flexibilidade e originalidade são essenciais para compreender o mundo contemporâneo e para poder ter condições de agir sobre ele, uma vez que as mudanças ocorrem de forma constante e rápida, sendo que a criatividade pode ser um diferencial no processo de adaptação às novas demandas cotidianas. Por isso, da mesma forma que outras habilidades são estimuladas e incentivadas, a criatividade deveria possuir um espaço especial no processo de formação dos indivíduos.

Do ponto de vista psicanalítico, em função da importância que a abordagem confere aos conteúdos inconscientes, pode-se compreender a criatividade como a expressão da subjetividade humana, fruto da equação entre a compreensão racional e a vivência irracional, a partir da interação entre tendências constitucionais e experiências vividas. Para tanto, esse processo considera os conteúdos do mundo interno e os fatos da realidade externa, com foco na manutenção, transformação e aprimoramento para a adaptação à vida (Oliveira, 2001).

Com o aprimoramento da compreensão do conceito da criatividade, foi observado a importância da influência de fatores de ordem social, cultural e histórica no desenvolvimento da capacidade criativa. Assim, a posição individual para compreender a criatividade, deu espaço, gradativamente para uma postura mais sistêmica para compreende-la (Alencar \& Fleith, 2003). Nesse sentido, Sternberg (2006) explica que a sociedade pode desempenhar importante papel no desenvolvimento da criatividade, pois o julgamento de uma ação criativa desde inovações simples, como elaboração e modificação de ideias já existentes, até contribuições verdadeiramente originais que mudam a concepção sobre determinado assunto - estão sujeitas a julgamento externo. Assim, o investimento de recursos criativos dependerá, fortemente, de como o ambiente 
avalia o que foi desenvolvido pelo indivíduo, em um plano de valorização e recompensas.

Nesse contexto, Ostrower (2012) compreende que a criatividade configurase como um potencial inerente ao ser humano e uma necessidade em seu processo de adaptação, pois indica a motivação para conferir nova forma a uma nova situação. Explica que a capacidade criativa é fruto da interligação de componentes individuais e valores culturais, no sentido de conferir um significado inovador e intencional, com valor e sentido social.

Do ponto de vista individual, Sakamoto (2007) assinala o grande desafio de identificar elementos que possam facilitar o desenvolvimento do fenômeno criativo, focando suas reflexões em três fatores: estado mental característico que gera abertura a novas possibilidades, atitude afetiva de comprometimento que indique uma disposição emocional na realização de um projeto e conjunto de recursos práticos materiais e intelectuais para o desenvolvimento da ideia. Nessa concepção, nota-se a importância conferida ao elemento afetivo no desenvolvimento da criatividade.

Objetivo

Descrever dados sobre a criatividade em acadêmicos do Curso de Psicologia, comparando os resultados obtidos em diferentes semestres com a finalidade de verificar se é possível a observação do desenvolvimento do potencial criativo durante o período de graduação.

\section{MÉTODO}

O grupo de participantes que viabilizou este estudo foi composto por 75 estudantes do Curso de Psicologia de uma Universidade particular situada na Grande São Paulo, sendo: 25 do primeiro semestre, 25 do quinto semestre e 25 do décimo semestre (formandos). Não foram observadas variáveis como sexo, idade ou nível socioeconômico visto que o que se buscou foi avaliar as características criativas nesta população.

Nakano e Wechsler (2007) apontam, em pesquisa sobre a produção científica brasileira acerca da criatividade, que tanto teses e dissertações como publicações periódicas tem voltado maior atenção para a investigação da criatividade em adultos com 48,1\% e 45,3\% respectivamente. No entanto, com relação ao nível educacional, nas teses e dissertações alunos de Ensino Superior estão em terceiro lugar, com 20,3\% e em segundo lugar nas publicações 
periódicas com 27,6\%, sendo a população de Ensino Fundamental a mais investigada.

Para a coleta de dados foi utilizado o Teste de Torrance - Versão Brasileira Avaliação da criatividade por palavras, considerando-se os objetivos traçados. Trata-se de um instrumento dos mais utilizados, juntamente com seu similar de forma figural, na literatura internacional (em sua versão original) e brasileira (em sua versão adaptada e padronizada), como medidas válidas e precisas para aferir a criatividade (Wechsler, 2004a).

Segundo Wechsler (2004a) as características do processo e da pessoa criativa têm sido estudadas com o objetivo de compreender quais atitudes, comportamentos e sentimentos definem uma pessoa com alta produtividade criativa. E em seu manual aponta cada uma das características criativas avaliadas pelo teste de criatividade verbal (versão brasileira), como descritas a seguir.

Fluência: é a capacidade de gerar um grande número de ideias e soluções para um problema específico;

Flexibilidade: é caracterizada pela habilidade de olhar para um problema sob diferentes ângulos e de mudar as propostas para solucioná-lo;

Elaboração: é a capacidade de acrescentar detalhes a uma ideia enriquecendo-a de informações gerando um sentido de harmonia e elegância estética;

Originalidade: é a capacidade de produzir ideias raras ou incomuns, quebrando padrões habituais e gerando respostas incomuns dentro de um grupo;

Expressão da Emoção: refere-se às influências de ordem não racional na produção criativa, ou seja, o poder das emoções no processo criativo é mais intenso que os de ordem cognitiva;

Fantasia: é a habilidade de transformar o mundo com imaginação, de ir para além do real, de transformar o impossível em possível;

Perspectiva Incomum: a pessoa criativa demonstra a necessidade de obter uma perspectiva incomum diante de fatos considerados inquestionáveis, é a capacidade de resistir às pressões da sociedade com atitude inconformista, porém, não deve ser confundida com rebeldia, uma vez que esta tende ao comportamento de crítica e a outra tende a apontar novas propostas e novos caminhos de ação; 
Uso de Analogias e Metáforas: é a habilidade de encontrar semelhanças entre coisas que não são percebidas como parecidas, é fazer conexões entre coisas desconexas oferecendo outra forma de pensar, sentir, descrever e visualizar a realidade.

Em pesquisa sobre a produção científica brasileira acerca da avaliação de criatividade, Nakano e Wechsler (2007) apontam o Teste de Torrance como o mais utilizado nos estudos sobre o tema, tanto em trabalhos de pós-graduação ( $N=21$ com 46,8\% dos instrumentos) como em artigos ( $N=14$ com 51,9\% dos testes).

Após a devida aprovação pelo Comitê de Ética em Pesquisa com Seres Humanos, quando do primeiro contato, o pesquisador explicou o propósito da investigação para os participantes. Após seu aceite, foi agendada uma data para a aplicação do instrumento, de acordo com a disponibilidade dos envolvidos. No dia da aplicação do instrumento, foi fornecido o Termo de Consentimento Livre e Esclarecido - TCLE para leitura e assinatura dos participantes.

Em seguida foi aplicado o Teste de Torrance - Versão Brasileira - Avaliação da criatividade por palavras, seguindo seus critérios de aplicação constantes no manual técnico do instrumento (Wechsler, 2004a). Segundo a autora, a aplicação do teste Pensando Criativamente com Palavras requer as mesmas condições ideais de aplicação que qualquer instrumento psicológico (ambiente silencioso, com instalações confortáveis, iluminação adequada e ausência de terceiros no local). O teste de criatividade verbal pode ser aplicado em forma individual ou grupal. Considerando que esta última forma é a mais comum, foi esta a utilizada neste trabalho, assim como, foi um facilitador devido à quantidade de participantes.

De acordo com seu manual específico, antes de entregar os cadernos de aplicação, o aplicador deve dar uma orientação tentando provocar interesse e motivação, para isso deve se familiarizar com todos os aspectos envolvidos na aplicação e as instruções devem ser lidas pelo fato de serem padronizadas. Após, pedir que os participantes abram os cadernos e realizar com os mesmos a leitura das orientações de cada atividade, aguardando o tempo concedido para a realização de cada uma. Cada caderno é composto de seis atividades e para as atividades $1,2,3$ e 5 é concedido o tempo de cinco minutos; e para as atividades 4 e 6 , dez minutos. Sendo assim, o tempo necessário para responder o teste verbal é de quarenta minutos, devendo também ser adicionado o tempo 
utilizado para as instruções preliminares, entrega dos testes e tirar dúvidas que surgirem antes do início (Wechsler, 2004a).

\section{RESULTADOS E DISCUSSÃO}

Após a aplicação dos testes, as respostas foram corrigidas, analisadas e cotadas de acordo com os procedimentos técnicos apresentados no manual do instrumento (Wechsler, 2004a). Os resultados foram agrupados por semestre e foi realizado tratamento estatístico no sentido de descrever o perfil da amostra estudada, além de comparar os resultados obtidos nos três grupos participantes do estudo: alunos do primeiro semestre, quinto semestre e décimo semestre do curso de psicologia.

Perfil dos participantes

Tabela 1.

Comparação da Idade entre os três grupos

\begin{tabular}{cccccc}
\hline \multicolumn{2}{c}{ Idade } & 10 sem. & 50 sem. & 100 sem. & $p$ \\
\hline \multirow{2}{*}{$<20$} & $\mathrm{~N}$ & 9 & 0 & 0 & \\
& $\%$ & $\mathbf{3 6 , 0 0}$ & 0,00 & 0,00 & \\
$20-29$ & $\mathrm{~N}$ & 10 & 14 & 12 & \\
& $\%$ & 40,00 & $\underline{\mathbf{5 6 , 0 0}}$ & $\frac{\mathbf{5 0 , 0 0}}{5}$ & 0,001 \\
$30-39$ & $\mathrm{~N}$ & 5 & $\mathbf{3}$ & 5 & \\
& $\%$ & 20,00 & $\mathbf{3 2 , 0 0}$ & 20,83 & \\
$40-49$ & $\mathrm{~N}$ & 0 & 2 & 5 & \\
& $\%$ & 0,00 & 8,00 & $\mathbf{2 0 , 8 3}$ & \\
$>=50$ & $\mathrm{~N}$ & 1 & 1 & 2 & \\
& $\%$ & 4,00 & 4,00 & 8,33 & \\
\hline
\end{tabular}

Como pode ser observado na Tabela 1 há diferenças significativas em relação à idade dos alunos que compuseram a amostra $(p=0,001)$. No primeiro semestre destaca-se um número significativo de alunos com 20 anos ou menos em comparação aos outros semestres. No quinto semestre a maioria concentrase na idade entre 20 e 29 anos e no décimo semestre, embora a maioria seja desta mesma faixa etária, há um aumento significativo na faixa dos 40 a 49 anos com relação aos outros semestres.

Em relação ao Sexo, o que se observa na Tabela 2 é uma maioria de mulheres em todos os semestres, sem diferenças significativas. 
Tabela 2. Comparação das variáveis do sexo entre os três grupos

\begin{tabular}{cccccc}
\hline & & 10 & $5^{\circ}$ & $10^{\circ}$ & \\
Sexo & sem. & sem. & sem. & \\
\hline \multirow{2}{*}{$\mathrm{F}$} & $\mathrm{N}$ & 15 & 21 & 20 & $\mathrm{X}^{2}=4,37$ \\
& $\%$ & 60,00 & 84,00 & 80,00 & $\mathrm{GL}=2$ \\
& $\mathrm{~N}$ & 10 & 4 & 5 & $p=0,113$ \\
$\mathrm{M}$ & $\%$ & 40,00 & 16,00 & 20,00 & \\
\hline
\end{tabular}

\section{Resultados do Teste de Torrance}

As informações obtidas por meio do Teste de Torrance, após análise estatística, foram divididas em duas partes:

- Os dados provenientes das variáveis categóricas de análise, que foram classificados de acordo com o que é estabelecido pelo manual do Teste (Wechsler, 2004a) e avaliados como valores inferiores $(\downarrow \downarrow)$ ), abaixo da média $(\downarrow)$, média $(=)$, acima da média $(\uparrow)$ e superiores $(\uparrow \uparrow)$, de acordo com as tabelas de desempenho da população normativa brasileira.

- Os dados provenientes das variáveis numéricas foram analisados considerando-se a análise estatística descritiva, a partir da média, desvio padrão, valores mínimo e máximo, mediana e quartis.

A interpretação psicológica dos resultados foi pautada integralmente nas orientações técnicas do teste, por meio das informações contidas no manual (Wechsler, 2004a).

\section{Variáveis Categóricas}

A Tabela 3 apresenta a comparação das variáveis categóricas de classificação das características de criatividade entre os três semestres alvo do presente estudo. São apresentados os dados referentes às oito dimensões estudadas pelo teste, além dos dois índices de criatividade verbal. Para a comparação dos dados entre os três grupos foram utilizados valores de frequência bruta $(\mathrm{N})$ e frequência relativa (\%) a partir da aplicação do Teste Exato de Fisher com nível de significância de 5\% $(p<0,05)$. 
Tabela 3.

Comparação das variáveis categóricas na avaliação da criatividade entre os três grupos

\begin{tabular}{|c|c|c|c|c|c|c|c|c|c|c|c|c|c|c|c|c|c|}
\hline \multirow{2}{*}{ Dado } & & \multicolumn{5}{|c|}{$1^{\circ}$ semestre } & \multicolumn{5}{|c|}{$5^{0}$ semestre } & \multicolumn{5}{|c|}{$10^{\circ}$ semestre } & \multirow{2}{*}{$p$} \\
\hline & & $\downarrow \downarrow$ & $\downarrow$ & $=$ & $\uparrow$ & $\uparrow \uparrow$ & $\downarrow \downarrow$ & $\downarrow$ & $=$ & $\uparrow$ & $\uparrow \uparrow$ & $\downarrow \downarrow$ & $\downarrow$ & $=$ & $\uparrow$ & $\uparrow \uparrow$ & \\
\hline \multirow{2}{*}{ FLU } & $\mathrm{N}$ & 2 & 5 & 16 & 2 & - & 1 & 1 & 14 & 8 & 1 & - & 2 & 9 & 13 & 1 & \multirow{2}{*}{0,010} \\
\hline & $\%$ & 8 & $\underline{20}$ & $\underline{64}$ & 8 & - & 4 & 4 & $\underline{56}$ & 32 & 4 & - & 8 & 36 & $\underline{52}$ & 4 & \\
\hline \multirow{2}{*}{ FLEX } & $\mathrm{N}$ & 3 & 3 & 19 & - & - & 3 & 2 & 18 & 2 & - & 1 & 1 & 19 & 4 & - & \multirow{2}{*}{0,425} \\
\hline & $\%$ & 12 & 12 & 76 & - & - & 12 & 8 & 72 & 8 & - & 4 & 4 & 76 & 16 & - & \\
\hline \multirow{2}{*}{ ELA } & $\mathrm{N}$ & - & 7 & 16 & 2 & - & - & - & 9 & 14 & 2 & - & - & 16 & 5 & 4 & \multirow{2}{*}{0,001} \\
\hline & $\%$ & - & $\underline{28}$ & 64 & 8 & - & - & - & 36 & $\underline{56}$ & 8 & - & - & $\underline{64}$ & 20 & 16 & \\
\hline \multirow{2}{*}{ ORI } & $\mathrm{N}$ & - & - & 17 & 7 & 1 & - & - & 8 & 13 & 4 & - & - & 4 & 15 & 6 & \multirow{2}{*}{0,003} \\
\hline & $\%$ & - & - & $\underline{68}$ & 28 & 4 & - & - & 32 & $\underline{52}$ & 16 & - & - & 16 & $\underline{60}$ & 24 & \\
\hline \multirow{2}{*}{ EMO } & $\mathrm{N}$ & - & 1 & 20 & 4 & - & - & 1 & 20 & 2 & 2 & - & 2 & 20 & 2 & 1 & \multirow{2}{*}{$p=0,818$} \\
\hline & $\%$ & - & 4 & 80 & 16 & - & - & 4 & 80 & 8 & 8 & - & 8 & 80 & 8 & 4 & \\
\hline \multirow{2}{*}{ FANT } & $\mathrm{N}$ & - & - & 19 & 4 & 2 & - & - & 23 & 2 & - & - & - & 18 & 7 & - & \multirow{2}{*}{$p=0,137$} \\
\hline & $\%$ & - & - & 76 & 16 & 8 & - & - & 92 & 8 & - & - & - & 72 & 28 & - & \\
\hline \multirow{2}{*}{ PIC } & $\mathrm{N}$ & - & - & 24 & 1 & - & - & - & 21 & 4 & - & - & - & 19 & 6 & - & \multirow{2}{*}{$p=0,163$} \\
\hline & $\%$ & - & - & 96 & 4 & - & - & - & 84 & 16 & - & - & - & 76 & 24 & - & \\
\hline \multirow{2}{*}{ ANA } & $\mathrm{N}$ & - & - & 12 & 8 & 5 & - & - & 17 & 8 & - & - & - & 17 & 7 & 1 & \multirow{2}{*}{$p=0,128$} \\
\hline & $\%$ & - & - & 48 & 32 & 20 & - & - & 68 & 32 & - & - & - & 68 & 28 & 4 & \\
\hline \multirow{2}{*}{ ICV1 } & $\mathrm{N}$ & - & 7 & 15 & 3 & - & - & 2 & 13 & 9 & 1 & - & 2 & 9 & 11 & 3 & \multirow{2}{*}{$p=0,025$} \\
\hline & $\%$ & - & $\underline{28}$ & $\underline{60}$ & 12 & - & - & 8 & $\underline{52}$ & $\underline{36}$ & 4 & - & 8 & 36 & $\underline{44}$ & $\underline{12}$ & \\
\hline \multirow{2}{*}{ ICV2 } & $\mathrm{N}$ & - & 7 & 13 & 5 & - & - & 3 & 10 & 10 & 2 & - & 2 & 9 & 10 & 4 & \multirow{2}{*}{$p=0,117$} \\
\hline & $\%$ & - & 28 & 52 & 20 & - & - & 12 & 40 & 40 & 8 & - & 8 & 36 & 40 & 16 & \\
\hline
\end{tabular}

Legenda 1: $\downarrow \downarrow$ - Valores Inferiores

$\downarrow$ - Valores Abaixo da Média

$=-$ Valores na Média

$\uparrow$ - Valores Acima da Média

$\uparrow \uparrow$ - Valores Superiores

FANT - Fantasia

PIC - Perspectiva Incomum

ANA - Analogia

ICV1 - Índice Criativo Verbal 1

ICV2 - Índice Criativo Verbal 2
Legenda 2: FLU - Fluência

FLEX - Flexibilidade

ELA - Elaboração

ORI - Originalidade

EMO - Emoção

No que se refere à Fluência, observa-se diferença estatisticamente significativa $(p=0,010)$, indicando maior desempenho nos resultados dos alunos do $10^{\circ}$ semestre, revelando que esses acadêmicos possuem maior capacidade em cultivar número abundante de ideias, o que possibilita encontrar soluções 
mais eficazes para problemas específicos, de acordo com o pressuposto de que quantidade traz qualidade. No entanto, embora os resultados mostrem um desempenho crescente pelos alunos neste estudo com relação à Fluência, o que se observa em pesquisa que buscou avaliar o percurso da criatividade figural do ensino médio ao ensino superior é que, em relação às séries estudadas, os alunos do $2^{\circ}$ ano universitário obtiveram melhor desempenho nesta característica, mostrando, assim, um desempenho não linear entre as séries universitárias avaliadas (Nakano \& Wechsler, 2006).

Quando se analisa a Flexibilidade, a comparação dos dados entre os três semestres não revelou diferenças significativas $(p=0,425)$, indicando que a habilidade de olhar determinado problema sob diferentes perspectivas e apresentar diferentes tipos de propostas para solucioná-lo não diferencia os grupos no que se refere ao semestre de estudo.

Ao se analisar as informações sobre Elaboração, nota-se uma melhor classificação entre os alunos do $5^{0}$ semestre $(p<0,001)$ na capacidade de acrescentar um sentido de harmonia e elegância estética a uma ideia, embelezando-a pelo acréscimo de detalhes e informações. Este processo exige persistência e trabalho, envolvendo planejamento e organização, no entanto, seu excesso pode diminuir a frequência de características como fluência e flexibilidade.

Os dados sobre Originalidade não apresentaram valores abaixo da média, com diferenças significativas entre os semestres nos valores acima da média, em que $010^{\circ}$ semestre obteve melhores resultados $(p=0,003)$ na capacidade de produzir ideias raras ou incomuns, quebrar padrões de pensamento, criando ou sugerindo mudanças para futuros produtos ou na maneira como a realidade é percebida, dentro de um determinado grupo de pessoas.

Em estudo com 18 estudantes universitários de diferentes áreas do conhecimento percebeu-se que, em termos gerais, há alunos muito criativos e muito pouco criativos em cada um dos grupos estudados. Em termos mais concretos, nesta amostra reduzida, os estudantes de Humanidades apresentaram desempenho superior em fluência, flexibilidade e originalidade nas provas verbais, o que, comparado aos resultados aqui obtidos, o mesmo é observado em relação à fluência e à originalidade (Bahia, 2008).

Em relação às características mais relacionadas aos aspectos afetivos da personalidade criativa: Emoção, Fantasia, Perspectiva Incomum e Analogia, não 
foram observadas diferenças significativas entre os três semestres com valores $p=0,818, p=0,137, p=0,163$ e $p=0,128$, respectivamente. Na característica Emoção evidenciam-se aspectos relacionados aos sentimentos com elementos de ordem não racional da expressão criativa; na Fantasia a habilidade de ir além do real para a imaginação e o sonho, transformando o mundo com a imaginação; na Perspectiva Incomum a capacidade de ter uma atitude inconformista frente a fotos considerados inquestionáveis, realizar de maneira diferente o que é tido como verdade imutável em determinado contexto; na Analogia (metáfora) a capacidade de estabelecer relações e buscar semelhanças entre coisas percebidas como diferentes, ou seja, buscar conexões entre elas.

No Índice Criativo Verbal 1 observam-se diferenças significativas entre os três semestres. No primeiro semestre o desempenho foi classificado entre Abaixo da Média e Média, no quinto semestre entre Média e Acima da Média e no décimo semestre, com melhor desempenho, entre Acima da Média e Superior $(p=0,025)$. Este índice é composto pela soma das características criativas: Fluência, Flexibilidade, Elaboração e Originalidade e sua relevância se concentra na compreensão da criatividade do ponto de vista do funcionamento cognitivo, no caso deste estudo, dos estudantes de psicologia que compuseram a amostra revelando que tal habilidade pode ser observada de forma mais desenvolvida nos alunos concluintes.

Já o Índice Criativo Verbal 2, obtido pela soma de todas as oito características criativas verbais, as quatro primeiras acima mais as já citadas anteriormente, que exprimem aspectos afetivos da personalidade criativa, não apresenta diferenças relevantes entre os grupos estudados $(p=0,117)$.

De modo geral, o que se observou na pesquisa de Nakano e Wechsler (2006) é que os alunos universitários obtiveram desempenho superior ao ensino médio em 11 das 13 características criativas avaliadas. No entanto, não foi um desempenho linear, em que foram avaliados alunos do $1^{0}$ ao $4^{\circ}$ anos universitários. Destacam-se os alunos do $3^{\circ}$ ano em Elaboração e Perspectiva Incomum, e os alunos do $2^{\circ}$ ano em Fluência, Flexibilidade, Originalidade e Fantasia. Já o que se observa neste estudo é que houve um desempenho crescente e significativo em características como Fluência, Originalidade e Índice Criativo Verbal 1 e não significativo em Flexibilidade, Emoção, Perspectiva Incomum e Índice Criativo Verbal 2. Somente na Elaboração obteve-se um melhor desempenho entre os alunos do $5^{\circ}$ semestre e um desempenho 
decrescente em Fantasia e Analogia, com melhores resultados obtidos pelos alunos do $1^{\circ}$ semestre.

Em estudo realizado com alunos concluintes do curso de psicologia detectou-se que, para $95 \%$ dos estudantes pesquisados, a criatividade é importante para o exercício da sua futura profissão, e em relação ao ser ou não criativo, $85 \%$ afirmaram que se consideravam pessoas criativas enquanto $15 \%$ da amostra responderam que não. Em relação à importância atribuída à criatividade para o psicólogo, 41,67\% acreditam ser um fator que facilite a atuação deste profissional e $25 \%$ acreditam ser importante para a solução de problemas (Campos \& Largura, 2000).

\section{Variáveis numéricas}

Além da análise das variáveis categóricas, foi realizada comparação dos dados a partir dos dados numéricos obtidos na avaliação da criatividade por meio do Teste de Torrance, na qual foram utilizados os dados brutos obtidos na correção dos testes e seus respectivos percentis de acordo com valores normativos apresentados no manual do instrumento (Wechsler, 2004a). Para a referida análise, foi utilizado o Teste de Kruskal-Wallis devido à ausência de distribuição normal das variáveis.

Tabela 4.

Comparação das variáveis numéricas sobre Fluência nos três grupos

\begin{tabular}{cccccccccc}
\hline \multicolumn{2}{c}{ Fluência } & Média & D.P. & Min & Q1 & Mediana & Q3 & Máx & $p$ \\
\hline $1^{0}$ & Bruto & 51,04 & 17,85 & 20,00 & 34,00 & 51,00 & 66,00 & 76,00 & \\
Sem & Percentil & 43,64 & 29,78 & 0,00 & 12,00 & 44,00 & 71,00 & 86,00 & \\
50 & Bruto & 69,16 & 26,06 & 27,00 & 50,00 & 69,00 & 81,00 & 128,00 & 0,001 \\
Sem & Percentil & 65,36 & 30,90 & 1,00 & 41,00 & 79,00 & 90,00 & 99,00 & \\
$10^{\circ}$ & Bruto & 79,48 & 27,25 & 25,00 & 60,00 & 82,00 & 94,00 & 144,00 & \\
Sem & Percentil & 75,84 & 26,00 & 3,00 & 63,00 & 88,00 & 92,00 & 99,00 & \\
\hline
\end{tabular}

Ao se analisar os dados numéricos referentes à Fluência, também é possível observar diferença significativa $(p<0,001)$ com melhor desempenho no referido aspecto sendo observado nos alunos do $10^{\circ}$ semestre. Em estudo de validação e precisão do instrumento de avaliação da criatividade verbal no contexto brasileiro, Wechsler (2004b) com uma amostra composta por 128 pessoas, sendo 63 definidas como criativas e 65 consideradas como não criativas ou regulares, observou-se que: em relação à Fluência, os não criativos obtiveram, 
em resultados brutos, média 55,8 e os criativos 74,1 . O que demonstra que, em comparação aos resultados aqui apresentados, os alunos do $10^{\circ}$ semestre obtiveram média ainda superior aos criativos, ou seja, 79,48.

Tabela 5.

Comparação das variáveis numéricas sobre Flexibilidade nos três grupos

\begin{tabular}{cccccccccc}
\hline \multicolumn{2}{c}{ Flexibilidade } & Média & D.P. & Min & Q1 & Mediana & Q3 & Máx & $p$ \\
\hline $1^{0}$ & Bruto & 22,88 & 6,48 & 11,00 & 19,00 & 24,00 & 28,00 & 36,00 & \\
Sem & Percentil & 32,36 & 21,63 & 1,00 & 16,00 & 36,00 & 51,00 & 63,00 & Bruto \\
$5^{\circ}$ & Bruto & 25,48 & 7,16 & 11,00 & 23,00 & 27,00 & 29,00 & 39,00 & 0,052 \\
Sem & Percentil & 43,56 & 27,60 & 1,00 & 25,00 & 46,00 & 56,00 & 93,00 & Percntl \\
$10^{\circ}$ & Bruto & 27,72 & 6,83 & 13,00 & 24,00 & 28,00 & 31,00 & 43,00 & 0,064 \\
Sem & Percentil & 51,52 & 27,34 & 1,00 & 34,00 & 51,00 & 73,00 & 96,00 & \\
\hline
\end{tabular}

Quando se analisa a Flexibilidade no que se refere a seus dados numéricos, assim como com relação as variáveis categóricas, não foram observadas diferenças significativas tanto em resultados brutos $(p=0,052)$ quanto em percentis $(p=0,064)$. Esses dados revelam, na comparação com o estudo de Wechsler (2004b), um desempenho geral não significativo dos alunos estudados, em que os alunos do $5^{\circ}$ semestre obtiveram média equivalente aos não criativos, com 25,48 e 26,4 respectivamente. Já os alunos do $10^{\circ}$ semestre foram menos criativos com média 27,72 em comparação aos criativos com valores em 31,1.

Tabela 6.

Comparação das variáveis numéricas sobre Elaboração nos três grupos.

\begin{tabular}{cccccccccc}
\hline \multicolumn{2}{c}{ Elaboração } & Média & D.P. & Min & Q1 & Mediana & Q3 & Máx & $p$ \\
\hline $1^{0}$ & Bruto & 6,20 & 4,98 & 0,00 & 2,00 & 5,00 & 9,00 & 17,00 & \\
Sem & Percentil & 39,88 & 28,59 & 5,00 & 13,00 & 30,00 & 62,00 & 88,00 & \\
50 & Bruto & 15,84 & 6,68 & 4,00 & 11,00 & 16,00 & 20,00 & 31,00 & \\
Sem & Percentil & 80,92 & 19,28 & 32,00 & 71,00 & 88,00 & 95,00 & 99,00 & 0,001 \\
$10^{\circ}$ & Bruto & 14,76 & 7,62 & 3,00 & 10,00 & 12,00 & 21,00 & 31,00 & \\
Sem & Percentil & 76,16 & 20,39 & 25,00 & 68,00 & 76,00 & 95,00 & 99,00 & \\
\hline
\end{tabular}

As variáveis numéricas sobre Elaboração demonstram diferenças significativas entre os grupos, com melhor desempenho pelo quinto semestre $(p<0,001)$, confirmando o que foi observado com os dados das variáveis categóricas. Demonstrando, na comparação, que os alunos do $5^{0}$ semestre obtiveram média 15,84 , superior aos criativos 14,6 e os do $10^{\circ}$ semestre com média equivalente em 14,76 (Wechsler, 2004b). 
Tabela 7.

Comparação das variáveis numéricas sobre Originalidade nos três grupos.

\begin{tabular}{cccccccccc}
\hline \multicolumn{2}{c}{ Originalidade } & Média & D.P. & Min & Q1 & Mediana & Q3 & Máx & $p$ \\
\hline $1^{0}$ & Bruto & 22,08 & 9,78 & 6,00 & 15,00 & 20,00 & 28,00 & 43,00 & \\
Sem & Percentil & 70,48 & 22,33 & 20,00 & 56,00 & 71,00 & 94,00 & 99,00 & \\
50 & Bruto & 31,16 & 14,30 & 6,00 & 22,00 & 29,00 & 40,00 & 66,00 & \\
Sem & Percentil & 83,48 & 19,40 & 22,00 & 80,00 & 92,00 & 97,00 & 99,00 & 0,001 \\
$10^{\circ}$ & Bruto & 39,92 & 15,06 & 13,00 & 30,00 & 42,00 & 48,00 & 75,00 & \\
Sem & Percentil & 91,64 & 13,32 & 50,00 & 93,00 & 97,00 & 98,00 & 99,00 & \\
\hline
\end{tabular}

No que se refere à Originalidade, assim como observado anteriormente, os resultados mostram um melhor rendimento pelos alunos do décimo semestre $(p<0,001)$. No entanto, em comparação ao estudo de Wechsler (2004b), mesmo o $1^{0}$ semestre com a menor média 22,08 obteve resultados significativos, já o $5^{0}$ e o $10^{\circ}$ semestres obtiveram médias com diferenças bastante significativas com valores 31,16 e 39,92 em comparação aos criativos com valores em 26,2. Porém, deve-se levar em conta a dificuldade envolvida na correção dos testes de criatividade, exigindo o julgamento daqueles que os corrigem devido à natureza da criatividade e ao formato dos testes que requerem respostas abertas e não previsíveis (Wechsler, 2004a).

Tabela 8.

Comparação das variáveis numéricas sobre Emoção nos três grupos.

\begin{tabular}{cccccccccc}
\hline \multicolumn{2}{c}{ Emoção } & Média & D.P. & Min & Q1 & Mediana & Q3 & Máx & $p$ \\
\hline $1^{0}$ & Bruto & 3,60 & 2,53 & 0,00 & 2,00 & 3,00 & 5,00 & 10,00 & \\
Sem & Percentil & 57,08 & 24,36 & 6,00 & 46,00 & 59,00 & 71,00 & 94,00 & Bruto \\
50 & Bruto & 3,92 & 3,82 & 0,00 & 2,00 & 4,00 & 4,00 & 17,00 & 0,681 \\
Sem & Percentil & 49,44 & 25,25 & 6,00 & 28,00 & 55,00 & 55,00 & 99,00 & Percntl \\
$10^{\circ}$ & Bruto & 4,20 & 3,23 & 0,00 & 2,00 & 4,00 & 6,00 & 14,00 & 0,277 \\
Sem & Percentil & 55,68 & 26,11 & 6,00 & 28,00 & 59,00 & 77,00 & 99,00 & \\
\hline
\end{tabular}

Tabela 9.

Comparação das variáveis numéricas sobre Fantasia nos três grupos.

\begin{tabular}{cccccccccc}
\hline \multicolumn{2}{c}{ Fantasia } & Média & D.P. & Min & Q1 & Mediana & Q3 & Máx & $p$ \\
\hline $1^{0}$ & Bruto & 3,24 & 4,43 & 0,00 & 0,00 & 2,00 & 3,00 & 16,00 & \\
Sem & Percentil & 59,28 & 27,08 & 17,00 & 40,00 & 57,00 & 73,00 & 99,00 & Bruto \\
50 & Bruto & 1,64 & 1,87 & 0,00 & 0,00 & 1,00 & 2,00 & 7,00 & 0,350 \\
Sem & Percentil & 47,48 & 24,26 & 17,00 & 39,00 & 39,00 & 70,00 & 93,00 & Percntl \\
$10^{\circ}$ & Bruto & 2,88 & 2,92 & 0,00 & 1,00 & 2,00 & 5,00 & 11,00 & 0,153 \\
Sem & Percentil & 60,48 & 27,30 & 17,00 & 40,00 & 65,00 & 86,00 & 97,00 & \\
\hline
\end{tabular}


Tabela 10.

Comparação das variáveis numéricas sobre Perspectiva Incomum nos três grupos.

\begin{tabular}{cccccccccc}
\hline \multicolumn{2}{c}{ Perspec. Inc. } & Média & D.P. & Min & Q1 & Mediana & Q3 & Máx & $p$ \\
\hline 10 & Bruto & 1,24 & 1,30 & 0,00 & 0,00 & 1,00 & 2,00 & 5,00 & \\
Sem & Percentil & 55,68 & 17,12 & 36,00 & 37,00 & 54,00 & 68,00 & 92,00 & Bruto \\
50 & Bruto & 1,72 & 2,32 & 0,00 & 0,00 & 1,00 & 2,00 & 10,00 & 0,206 \\
Sem & Percentil & 57,92 & 20,28 & 37,00 & 37,00 & 54,00 & 68,00 & 98,00 & Percntl \\
$10^{\circ}$ & Bruto & 2,56 & 2,62 & 0,00 & 0,00 & 2,00 & 3,00 & 9,00 & 0,245 \\
Sem & Percentil & 65,72 & 22,34 & 36,00 & 37,00 & 68,00 & 82,00 & 98,00 & \\
\hline
\end{tabular}

Tabela 11.

Comparação das variáveis numéricas sobre Analogia nos três grupos.

\begin{tabular}{cccccccccc}
\hline \multicolumn{2}{c}{ Analogia } & Média & D.P. & Min & Q1 & Mediana & Q3 & Máx & $p$ \\
\hline $1^{0}$ & Bruto & 3,32 & 3,05 & 0,00 & 0,00 & 3,00 & 6,00 & 9,00 & \\
Sem & Percentil & 73,28 & 26,70 & 32,00 & 51,00 & 87,00 & 98,00 & 99,00 & Bruto \\
50 & Bruto & 2,72 & 2,57 & 0,00 & 1,00 & 2,00 & 4,00 & 9,00 & 0,608 \\
Sem & Percentil & 68,56 & 24,66 & 32,00 & 51,00 & 70,00 & 91,00 & 98,00 & Percntl \\
$10^{\circ}$ & Bruto & 2,24 & 2,13 & 0,00 & 1,00 & 1,00 & 4,00 & 7,00 & 0,378 \\
Sem & Percentil & 66,88 & 23,77 & 32,00 & 51,00 & 79,00 & 88,00 & 99,00 & \\
\hline
\end{tabular}

Nas Tabelas 8, 9, 10 e 11, ao se analisar os resultados expostos, observase que os dados corroboram os obtidos na tabela 3 no que se refere às características de Emoção (Bruto $p=0,681$ e Percentil $p=0,277$ ), Fantasia (Bruto $p=0,350$ e Percentil $p=0,153$ ), Perspectiva Incomum (Bruto $p=0,206$ e Percentil $p=0,245$ ) e Analogia (Bruto $p=0,608$ e Percentil $p=0,378$ ), sendo assim, não demonstram diferenças significativas quando se comparam os três semestres estudados. A despeito desses resultados, em relação à Emoção, o que se observa em comparação à investigação de Wechsler (2004b) é que os alunos estudados obtiveram médias equivalentes aos não criativos, com média 4,3 destes. O que ocorre também em relação à Fantasia e à Perspectiva Incomum. Já o que se observa em Analogia, no estudo referido, é que não houve diferença que pudesse discriminar as pessoas criativas, 2,0, das não criativas, 1,9, porém os alunos do $1^{\circ}$ semestre obtiveram média com diferença significativa, 3,32 . 
Tabela 12.

Comparação das variáveis numéricas sobre ICV 1 nos três grupos.

\begin{tabular}{cccccccccc}
\hline \multicolumn{2}{c}{ ICV 1 } & Média & D.P. & Min & Q1 & Mediana & Q3 & Máx & $p$ \\
\hline $1^{0}$ & Bruto & 101,9 & 33,18 & 47,00 & 70,00 & 103,0 & 129,0 & 164,0 & \\
Sem & Percentil & 45,96 & 30,64 & 4,00 & 14,00 & 47,00 & 78,00 & 89,00 & \\
50 & Bruto & 140,9 & 48,01 & 58,00 & 115,0 & 140,0 & 166,0 & 250,0 & \\
Sem & Percentil & 71,12 & 29,50 & 4,00 & 67,00 & 84,00 & 92,00 & 99,00 & $<0,001$ \\
$10^{\circ}$ & Bruto & 161,7 & 51,98 & 58,00 & 123,0 & 166,0 & 201,0 & 275,0 & \\
Sem & Percentil & 81,36 & 24,56 & 4,00 & 75,00 & 92,00 & 97,00 & 99,00 & \\
\hline
\end{tabular}

Como é possível verificar na Tabela 12, referente ao Índice Criativo Verbal 1 , os resultados encontrados, assim como no índice das variáveis categóricas, demonstram melhor desempenho nos alunos do décimo semestre em comparação aos outros. Esses mesmos alunos, em comparação ao estudo de Wechsler (2004a) obtiveram resultados significativamente superiores com média 161,7 quando se relaciona aos criativos, com 131,4. O mesmo ocorre com o ICV2, porém, com menor significância com média 173,8 dos alunos do $10^{\circ}$ semestre e média 163,2 dos criativos, como pode ser observado na tabela a seguir.

Tabela 13.

Comparação das variáveis numéricas sobre ICV 2 nos três grupos.

\begin{tabular}{cccccccccc}
\hline \multicolumn{2}{c}{ ICV 2 } & Média & D.P. & Min & Q1 & Mediana & Q3 & Máx & $p$ \\
\hline $1^{0}$ & Bruto & 113,2 & 37,91 & 52,00 & 80,00 & 116,0 & 137,0 & 194,0 & \\
Sem & Percentil & 47,36 & 30,93 & 4,00 & 13,00 & 53,00 & 72,00 & 95,00 & \\
$5^{0}$ & Bruto & 151,6 & 53,79 & 64,00 & 120,0 & 152,0 & 174,0 & 287,0 & $<0,001$ \\
Sem & Percentil & 69,40 & 30,97 & 4,00 & 56,00 & 84,00 & 90,00 & 99,00 & \\
$10^{\circ}$ & Bruto & 173,8 & 56,38 & 63,00 & 134,0 & 171,0 & 210,0 & 300,0 & \\
Sem & Percentil & 79,88 & 25,27 & 4,00 & 72,00 & 89,00 & 97,00 & 99,00 & \\
\hline
\end{tabular}

No que se refere ao Índice Criativo Verbal 2, os resultados numéricos divergem dos dados encontrados nas variáveis categóricas, evidenciando, assim como no ICV 1, um melhor resultado obtido pelos alunos do décimo semestre, revelando maior capacidade criativa destes alunos em comparação aos alunos dos semestres anteriores.

Em síntese, o que pode ser observado neste estudo, principalmente nos índices ICV1 e ICV2, é que houve um aumento gradativo da capacidade criativa dos alunos de psicologia quando se comparou o desempenho entre os semestres do início, meio e final do curso, revelando a importância de se desenvolver 
espaços na graduação em psicologia para a expressão e desenvolvimento desta capacidade que se revela tão importante para o trabalho do psicólogo. Relativamente os resultados aqui obtidos corrobora-se a pesquisa de Campos e Largura (2000) que observaram que $60 \%$ de sua amostra acredita que às vezes ocorre espaço no curso de psicologia para a expressão da criatividade, $20 \%$ responderam frequentemente e sempre e os outros $20 \%$ responderam raramente e nunca.

Silva e Nakano (2012), em estudo com objetivo de investigar a produção científica sobre criatividade no contexto educacional em quinze anos, de 1995 a 2009, ao realizarem análise agrupando os estudos em períodos de cinco anos, verificaram que há um aumento significativo nas publicações, visto que, nos cinco primeiros anos pesquisados foi encontrado um total de 16 publicações, nos próximos cinco anos pesquisados, 67 publicações e este ritmo mantém-se no último período, quando são encontrados 39 trabalhos, salientando-se o fato de o último ano ainda não contemplar os trabalhos acadêmicos, indicando que o interesse na área parece bastante recente no Brasil. Os resultados demonstraram que a maior parte dos estudos sobre criatividade no contexto educacional foi desenvolvida com adultos $(n=39)$, no entanto chama a atenção o fato dos professores, principalmente de escolas de ensino fundamental e médio, comporem as amostras mais frequentes. Percebe-se, dessa forma, que atualmente a ampliação de estudos sobre criatividade no contexto educacional se deve à constatação de sua importância tanto para os avanços esperados na área da educação, quanto para o desenvolvimento dos alunos.

A temática da criatividade, neste sentido, tem promovido reflexões, como apontam Alencar (2002) e Castanho (2000) quando explicam a necessidade de se colocar em pauta a discussão de como os professores podem estimular a criatividade dos alunos no ambiente universitário. Nessa linha, Alencar e Fleith (2004) desenvolveram estudo para construção e validação de instrumento que permita avaliar a percepção de alunos universitários quanto às práticas docentes que favoreçam e estimulem o desenvolvimento e a expressão criativa e Alencar e Fleith (2010), em estudo com objetivo de validar uma escala para avaliar a percepção de professores da educação superior quanto à extensão em que utilizam práticas docentes que favorecem o desenvolvimento e expressão da criatividade do aluno. 


\section{CONSIDERAÇÕES FINAIS}

Apresenta-se uma reflexão sobre a importância da criatividade, como característica psicológica nas atividades dos indivíduos, com foco no recurso criativo de um grupo de estudantes do Curso de Psicologia. Durante o processo de formação em psicologia, busca-se o desenvolvimento de amplo conjunto de conhecimentos técnicos e habilidades para o desenvolvimento da prática psicológica de forma eficiente. Nesse cenário, a capacidade criativa pode ser importante recurso para que os futuros profissionais desenvolvam estratégias de atuação de forma inovadora, que busquem a superação de inevitáveis obstáculos que surgirão durante suas atividades cotidianas.

Os dados indicaram aumento do Índice de Criatividade em alunos concluintes do Curso de Psicologia, principalmente quanto às variáveis de fluência e originalidade. Assim, é possível conjecturar que o processo de formação em Psicologia, a partir de seus conteúdos teóricos e atividades práticas, pode ter contribuído para o desenvolvimento da habilidade criativa dos estudantes, principalmente no que tange à produção abundante de ideias novas e incomuns.

Considerando-se as habilidades necessárias para o exercício da profissão de forma crítica e inovadora, tais recursos criativos podem garantir a promoção de estratégias para identificar problemas e para o desenvolvimento de ações com vistas à busca de soluções favoráveis em vários campos de atuação do psicólogo.

Pelo fato da criatividade ser um tema em que muitas abordagens se debruçam para compreendê-lo, trazê-lo à tona na perspectiva específica da formação do psicólogo e relacioná-lo aos estudos já existentes foi uma forma de enriquecê-los, ou, quem sabe, CRIAR novas perspectivas. Nas pesquisas realizadas para a realização deste estudo, observou-se ser um tema em que a maioria dos trabalhos estão voltados à busca da relação entre níveis de ensino, processo ensino/aprendizagem e desenvolvimento da criatividade. Assim, o que se pretende com esta pesquisa é estimular novos estudos, visto que os resultados foram promissores, pois, percebeu-se que o curso de psicologia promoveu o desenvolvimento de características criativas específicas entre os alunos dos semestres estudados. 


\section{REFERÊNCIAS}

Alencar, E.M.L.S. (1995). Criatividade. (2a ed.). Brasília: Editora Universidade de Brasília.

Alencar, E.M.L.S. (2002). O contexto educacional e sua influência na criatividade. Linhas Críticas, 8(15), 165-178.

Alencar, E.M.L.S. \& Fleith, D.S. (2003). Contribuições teóricas recentes ao estudo da criatividade. Psicologia: Teoria e Pesquisa, 19(1), 1-8.

Alencar, E.M.L.S. \& Fleith, D.S. (2004). Inventário de práticas docentes que favoreçam a criatividade no ensino superior. Psicologia: Reflexão e Crítica, 17(1), 105-110.

Alencar, E.M.L.S. \& Fleith, D.S. (2010). Escala de práticas docentes para a criatividade na educação superior. Avaliação Psicológica, 9(1), 13-24.

Bahia, S. (2008). Criatividade e universidade entrecruzam-se? Sísifo: Revista de Ciência da Educação, 7, 51-62. Recuperado em 15 de maio de 2014 de http://www.academia.edu/265415/Criatividade_E_Universidade_Entrecruza m-se.

Campos, K.C.L. \& Largura, W.A.N. (2000). Criatividade na formação de psicólogos: Percepção de alunos. Psicologia Escolar e Educacional, 4(2), 1119.

Castanho, M.E.L.M. (2000). A criatividade na sala de aula universitária. In: I.P. Veiga \& M.E.L.M. Castanho (Orgs.), Pedagogia universitária: A aula em foco. (pp. 75-89.). São Paulo: Papirus.

Justo, J.S. (2001). Criatividade no mundo contemporâneo. In: M.S. Vasconcelos (Org.), Criatividade: Psicologia, educação e conhecimento do novo. (pp. 59-78). São Paulo: Moderna.

Nakano, T.C. \& Wechsler, S.M. (2006). O percurso da criatividade figural do ensino médio ao ensino superior. Boletim de Psicologia, 56(125), 205-219.

Nakano, T.C. \& Wechsler, S.M. (2007). Criatividade: Características da produção científica brasileira. Avaliação Psicológica, 6(2), 261-270.

Oliveira, M.L. (2001). Contribuições da psicanálise para a compreensão da criatividade. In: M.S. Vasconcelos (Org.), Criatividade: Psicologia, educação e conhecimento do novo. (pp. 21-42). São Paulo: Moderna.

Ostrower, F. (2012). Criatividade e processos de criação. (27a ed.). Petrópolis: Vozes. 
Sakamoto, C.K. (2000). Criatividade: Uma visão integradora. Psicologia: Teoria e Prática, 2(1), 50-58.

Sakamoto, C.K. (2007). As mil e uma realidades da experiência criadora: Uma metáfora do gênio criativo. In: C.K. Sakamoto (Org.), Um olhar criativo sobre a prática em psicologia: Proposições teóricas e técnicas (pp. 17-27). São Paulo: Editora Mackenzie.

Silva, T.F. \& Nakano, T.C. (2012). Criatividade no contexto educacional: análise de publicações periódicas e trabalhos de pós-graduação na área da psicologia. Educação e Pesquisa, 38(3), 743-759.

Sternberg, R.J. (2006). The nature of creativity. Creativity Research Journal, 18 (1), p. 87-98. Recuperado em 16 de Agosto de 2013 de versler, S.M. (2004a). Avaliação da criatividade por palavras - Teste de Torrance. Versão Brasileira. (2a ed. rev. ampl.). Campinas: IDB.

Wechsler, S.M. (2004b). Avaliação da criatividade verbal no contexto brasileiro. Avaliação Psicológica, 3(1), 21-31.

Contato: martaluisaa@gmail.com, castro.pf@uol.com.br

Recebido em: 25/06/2014

Revisado em: 29/07/2014

Aceito em: 11/08/2014 